
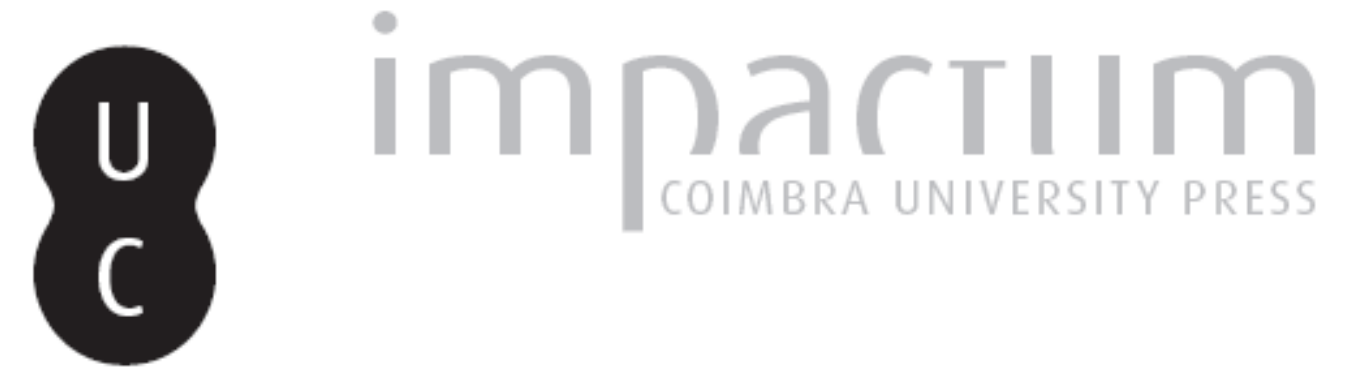

\title{
A reforma de 2007 do sistema público de pensões em Portugal: uma análise crítica das escolhas normativas implícitas
}

Autor(es): $\quad$ Murteira, Maria Clara

Publicado por: Faculdade de Economia da Universidade de Coimbra

URL persistente:

URI:http://hdl.handle.net/10316.2/25247

DOI:

DOI:http://dx.doi.org/10.14195/2183-203X_28_3

Accessed : $\quad$ 26-Apr-2023 15:41:31

A navegação consulta e descarregamento dos títulos inseridos nas Bibliotecas Digitais UC Digitalis, UC Pombalina e UC Impactum, pressupõem a aceitação plena e sem reservas dos Termos e Condições de Uso destas Bibliotecas Digitais, disponíveis em https://digitalis.uc.pt/pt-pt/termos.

Conforme exposto nos referidos Termos e Condições de Uso, o descarregamento de títulos de acesso restrito requer uma licença válida de autorização devendo o utilizador aceder ao(s) documento(s) a partir de um endereço de IP da instituição detentora da supramencionada licença.

Ao utilizador é apenas permitido o descarregamento para uso pessoal, pelo que o emprego do(s) título(s) descarregado(s) para outro fim, designadamente comercial, carece de autorização do respetivo autor ou editor da obra.

Na medida em que todas as obras da UC Digitalis se encontram protegidas pelo Código do Direito de Autor e Direitos Conexos e demais legislação aplicável, toda a cópia, parcial ou total, deste documento, nos casos em que é legalmente admitida, deverá conter ou fazer-se acompanhar por este aviso.

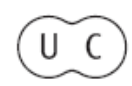




\section{N $\odot$ T $A E G \odot N O M I C A S$}

\section{ARGENTINO PESSOA MULTINATIONAL CORPORATIONS, FOREIGN INVESTMENT, AND ROYALTIES AND LICENSE FEES: EFFECTS ON HOST-COUNTRY TOTAL FACTOR PRODUCTIVITY}

ORLANDO GOMES TIME PREFERENCE AND CYCLICAL ENDOGENOUS GROWTH IN AN AK GROWTH MODEL

\section{$-3$}

$\rightarrow$

c.

6

3

$\theta$

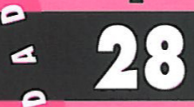

-

$\omega$

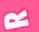

w

$\Rightarrow$

-

$z$

E

$a$

a

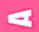

-

EF

$\odot$

$z$

$\odot$

v

w

w

a

w

0

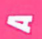

0

$\sim$

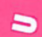

ن 
No presente artigo defende-se a necessidade de atribuir um papel central à função social dos sistemas de pensões no processo de formulação de políticas neste domínio, avaliando os efeitos das medidas adoptadas sobre os níveis de rendimento garantidos. Seguindo esta linha argumentativa, efectua-se uma avaliação crítica da reforma de 2007 do sistema de pensões em Portugal. Desenvolvida com o intuito de assegurar o equilíbrio financeiro do sistema, a reforma é objecto de crítica por duas razões fundamentais: pelo seu impacto negativo no bem-estar dos pensionistas; e por se afigurar metodologicamente inconsistente na óptica da política social, pois realiza o ajustamento através da diminuição da garantia de rendimento, negligenciando os objectivos sociais do sistema. Finalmente, propõe-se uma metodologia alternativa de formulação de políticas que principia pela definição de objectivos para a garantia de rendimento na reforma.
Un processus cohérent de réforme des retraites doit considérer la fonction sociale des systèmes des pensions comme étant fondamental. En conséquence, il doit évaluer les effets des politiques sur les revenus assurés aux retraités. Ainsi, l'article examine la réforme des retraites mise en place au Portugal en 2007. La réforme a eu pour objectif principal d'assurer l'équilibre financier à long terme du système des pensions et peut être critiquée pour deux raisons fondamentales: les effets négatifs des mesures introduites sur le bien-être des retraités; et son incohérence méthodologique du point de vue de la politique sociale, puisque le niveau des prestations a été pris comme variable d'ajustement et, donc, les objectifs sociaux du système ont été négligés. Ensuite, l'article propose une autre méthodologie qui formule, au départ, les objectifs à poursuivre en matière de revenus à assurer aux retraités.

This paper aims to emphasize the idea that the social function of pension systems should be a matter of primary concern when pension policies are designed. Thus, it is fundamental to assess the effects of policies on the income support guaranteed. Taking this view into consideration, the paper develops a critical assessment of the reform of the Portuguese pension system introduced in 2007. Designed to achieve financial sustainability, the reform is criticized for two main reasons: its negative effects on pensioners' welfare; and its incoherent methodology, because the income guarantee was taken as the adjustment variable and, as a result, the social objectives of the system were neglected. Finally, an alternative methodology for policy formulation that takes income security in retirement as the starting point is proposed. 


\section{Introdução}

O nível de rendimentos assegurado aos pensionistas na velhice não tem sido objecto da devida atenção na literatura económica e no discurso político. As análises de cariz económico e político sobre o futuro das pensões têm consagrado como tema central o previsível acréscimo da despesa decorrente do envelhecimento populacional. Esta preocupação tem motivado diversas reformas introduzidas nos sistemas de protecção social, em países da Europa e de outras partes do mundo. Nem sempre têm sido salientadas, porém, as consequências negativas, de um ponto de vista de bem-estar, da tentativa de conter os custos dos sistemas. Os efeitos da contenção da despesa em pensões podem-se revelar particularmente gravosos em países que não garantem ainda uma considerável segurança de rendimento à maior parte da população reformada. Tal é o caso português, em que o âmbito material dos direitos garantidos é ainda limitado.

Este artigo desenvolve uma reflexão crítica sobre as reformas recentemente introduzidas no sistema público de pensões em Portugal. No ponto 1, descrevem-se as alterações regulamentares recentes, referindo as características gerais do sistema em vigor antes da introdução das reformas e as linhas gerais do novo esquema. No ponto 2, efectua-se uma análise crítica das reformas mencionadas destacando dois aspectos: o seu impacto negativo no bem-estar dos pensionistas; e a sua formulação, metodologicamente inconsistente na perspectiva da política social, por negligenciar os objectivos sociais do sistema. No ponto 3 , efectua-se uma breve alusão a estratégias alternativas para lidar com o envelhecimento demográfico. No ponto 4, propõe-se uma metodologia para a formulação de políticas que se concentra na função social do sistema e, consequentemente, toma como ponto de partida a garantia de rendimento na reforma. Finalmente, no ponto 5, apresentam-se algumas notas conclusivas.

\section{As Alterações Regulamentares Introduzidas}

Neste ponto analisam-se os traços fundamentais da regulamentação do regime geral de segurança social dos trabalhadores dependentes do sector privado, no que se refere às condições de atribuição da pensão e ao respectivo método de cálculo, comparando o esquema anterior com o que foi recentemente introduzido.

O esquema que vigorava anteriormente reconhecia o direito à pensão de velhice quando o beneficiário atingia a idade legal da reforma, de sessenta e cinco anos, e um período mínimo de registo de remunerações ou equivalente ${ }^{1}$ (períodos de doença, maternidade, assistência à família, serviço militar, etc.), de quinze anos, com, pelo menos, cento e vinte dias de densidade contributiva.

Com a entrada em vigor do Decreto-Lei n. ${ }^{\circ} 329 / 93$, a regra de cálculo da pensão passou a ser a seguinte: $P E=2 \% \times n \times R R$, onde a sigla "PE" designa a pensão estatutária, "n" o número de anos de contribuições e "RR" a remuneração de referência. A última determinava-se tendo em conta as remunerações dos dez anos de melhores remunerações dos últimos quinze anos de actividade. As remunerações consideradas passam então a ser actualizadas de acordo com coeficientes definidos por Portaria, tendo em conta o índice de preços no consumidor sem

1 Ao longo do tempo as condições de atribuição das pensões foram sofrendo alterações. O Decreto-Lei n. ${ }^{\circ} 329 / 93$, de 25 de Setembro, introduziu alterações significativas a este nível. É de salientar que a idade legal da reforma das mulheres, até 1994, era mais baixa, sessenta e dois anos, tendo aumentado gradualmente (seis meses em cada ano) para sessenta e cinco anos. No que se refere ao prazo de garantia, os requisitos modificam-se ao longo do tempo. Sendo inicialmente exigido um prazo de garantia de cinco anos, entre 1988 e 1994, a lei passa a exigir um mínimo de dez anos de contribuições, independentemente do número de meses com registo de remunerações. 
habitação ${ }^{2}$. O montante estatutário da pensão deveria necessariamente estar compreendido entre $30 \%$ e $80 \%$ da remuneração de referência. A lei, porém, vem garantir um nível mínimo de pensão. Em consequência, o montante da primeira pensão pode ultrapassar o valor definido pela fórmula de cálculo, devido às regras de garantia de níveis mínimos. A partir de $1999^{3}$, os níveis mínimos passam a ser escalonados em função do número de anos de contribuições, correspondendo a diferentes percentagens da remuneração mínima nacional.

A lei garantia a indexação regular das prestações. Os acréscimos periódicos ou extraordinários das pensões seguiram o princípio da discriminação positiva, que envolve um acréscimo relativo superior das pensões mais baixas. Esta política permitiu um acréscimo de poder de compra das prestações de nível mínimo. Assim, entre 1986 e 2005, o crescimento nominal do nível mínimo de pensão foi superior à taxa de inflação (ver Quadro 1, em Anexo).

Os níveis mínimos de pensões cresceram com o propósito explícito de indexar o nível mínimo da pensão à remuneração mínima nacional. A Portaria n. ${ }^{\circ} 800 / 98$, de 22 de Setembro, consagrou o direito a um valor mínimo de pensão de velhice equiparado ao valor da remuneração mínima nacional (deduzido da taxa contributiva do trabalhador dependente) para os titulares que tenham cumprido uma carreira contributiva completa. Para os pensionistas com carreira incompleta, são definidos escalões de níveis mínimos que representam uma percentagem da remuneração mínima nacional (líquida da contribuições). A Lei n. ${ }^{\circ}$ 32/2002, de 20 de Dezembro, definiu um período de transição para alcançar o objectivo de convergência, findo o qual o nível mínimo das prestações deveria igualar a remuneração mínima (líquida de contribuições). Em $2005^{4}$, os beneficiários que apresentavam mais de trinta anos de contribuições atingem efectivamente tal objectivo e os que apresentavam carreiras mais curtas passam a receber prestações que correspondem a diferentes percentagens desse valor (entre $65 \%$ e $100 \%)$.

No ano de 2002, ocorre uma importante alteração regulamentar que modifica a fórmula de cálculo das prestações ${ }^{5}$. As novas regras estabelecem que o nível da pensão passe a ser calculado com base numa remuneração de referência dependente das remunerações de toda a carreira contributiva. Contudo, a lei definia um período de transição, entre 2002 e 2016, ao longo do qual o método de cálculo mais favorável poderia ser usado para determinar o valor das pensões. Assim, os efeitos da introdução de novas regras não estavam a ser plenamente sentidos em 2007, ano em que é introduzida uma nova lei. O Decreto-Lei n. ${ }^{\circ}$ 187/2007, de 10 de Maio, vem modificar a regra de cálculo das pensões de velhice e acelerar a transição para a fórmula de cálculo que faz depender a remuneração de referência e, assim, o nível da pensão, das remunerações da toda a carreira contributiva.

No que diz respeito às alterações legislativas recentes, entre as medidas introduzidas ${ }^{6}$, salientam-se três que se sumariam de seguida.

Uma das medidas consistiu na introdução de um "factor de sustentabilidade", que provoca a redução do valor da pensão à medida que a esperança de vida aumenta. Tal factor é definido pelo quociente entre a esperança de vida em 2006 e a esperança de vida no ano anterior à reforma. Este coeficiente, com valor inferior à unidade e decrescente à medida que a esperança de vida aumenta, será multiplicado pelo valor estatutário da pensão. A operação referida irá

2 Antes da entrada em vigor do Decreto-Lei n. ${ }^{\circ} 329 / 93$, de 25 de Setembro, não era efectuada a actualização das remunerações anteriores.

3 Portaria n. ${ }^{\circ} 1018 / 98$, de 4 de Dezembro.

4 Portaria n. ${ }^{\circ} 1316 / 2005$, de 22 de Dezembro.

5 Decreto-Lei n. ${ }^{\circ} 35 / 2002$, de 19 de Fevereiro, de acordo com a Lei n. ${ }^{\circ} 32 / 2000$, de 8 de Agosto.

$6 \mathrm{Na}$ análise que se segue refere-se apenas ao regime geral de segurança social. É de salientar que foram tomadas medidas de relevo tendentes a harmonizar o esquema que abrange os beneficiários da Caixa Geral de Aposentações com o esquema público. Ver Lei n. ${ }^{\circ}$ 60/2005 de 29 de Dezembro. É de salientar que o Decreto-Lei n. ${ }^{\circ} 187 / 2007$ também se aplica ao cálculo das pensões dos trabalhadores da Administração Pública admitidos depois de 1 de Setembro de 1993, nos termos do Decreto-Lei n. ${ }^{\circ}$ 286/93. 
produzir uma redução gradual do valor da pensão em relação ao seu nível estatutário. A lei introduz, porém, mecanismos que podem compensar o decréscimo tendencial do valor das prestações. Para tal, será necessário que os trabalhadores prolonguem o período activo ou que aceitem aumentar as suas contribuições.

A referida mudança da regra de cálculo das pensões é a medida que suscita uma maior reflexão. $\mathrm{O}$ direito à pensão de velhice é reconhecido se o beneficiário apresentar um período de contribuições mínimo de quinze anos. A pensão é determinada a partir de uma remuneração de referência que passa a depender das remunerações auferidas ao longo de toda a carreira contributiva. Desde 1994, os níveis de pensões são calculados com base no valor médio das remunerações auferidas nos melhores dez anos de remunerações dos últimos quinze anos de actividade. Tal regra tinha sido já modificada pelo Decreto-Lei n. ${ }^{\circ} 17 / 2000$, de 8 de Agosto, que estabelecia que o cálculo da pensão considerasse, gradualmente, as remunerações de toda a carreira contributiva (art. 57. $.^{\circ}-3$ ). Esta alteração regulamentar relativamente ao esquema introduzido pelo Decreto-Lei n. ${ }^{\circ} 329 / 93$, de 25 de Setembro, é significativa. O novo método de cálculo só foi adoptado com a entrada em vigor do Decreto-Lei n. ${ }^{\circ} 35 / 2002$, de 19 de Fevereiro. Como, porém, a lei estabelecia um período de transição, durante o qual os dois métodos, ou uma combinação de ambos, poderiam ser aplicados para o cálculo da pensão ${ }^{7}$, de forma a garantir aos beneficiários o regime mais favorável, o verdadeiro impacto de tal medida foi reduzido ${ }^{8}$. A pensão podia ser calculada de três formas: de acordo com as regras de cálculo anteriores, sendo a remuneração de referência equivalente à média dos melhores dez anos de remunerações dos últimos quinze; de acordo com a nova regra, dependendo das remunerações de toda a carreira contributiva; ou com base numa média ponderada dos dois valores anteriores.

A reforma introduzida pelo Decreto-Lei n. ${ }^{\circ}$ 187/2007, de 10 de Maio, vem acelerar a transição para a nova regra de cálculo. Doravante, os beneficiários, inscritos até ao final do ano de 2001 , terão a respectiva pensão calculada com base numa média ponderada de duas componentes: a primeira determina-se tendo em conta os melhores dez anos de remunerações dos últimos quinze anos de actividade; a segunda considera as remunerações de toda a carreira contributiva. A ponderação de cada componente depende do momento da reforma (anterior ou posterior a 31/12/2016) e do número de anos de contribuições anterior e posterior a um momento de referência (31/12/2006, para os que se reformem até 2016, e 31/12/2001, para os que se reformem depois dessa data). Para os beneficiários inscritos depois de 31/12/2001, a pensão será calculada com base nas remunerações de toda a carreira contributiva.

O terceiro aspecto que merece destaque relaciona-se com o método de indexação das prestações. Em 2006, foram adoptadas novas regras neste domínio ${ }^{9}$, com efeitos a partir do ano seguinte. Por um lado, a indexação das prestações deixa de estar dependente apenas da inflação, passando a relacionar-se, também, com o ritmo de crescimento económico. Por outro lado, a remuneração mínima nacional deixa de ser tomada como referência para a indexação das prestações de nível mínimo. Um novo termo de referência, o "Indexante de Apoios Sociais" (IAS), passa a ser usado para calcular as prestações e a sua actualização. O valor do IAS é definido anualmente pelo governo. Em 2007, o IAS foi determinado com base no valor da remuneração mínima nacional e do índice de preços no consumidor ${ }^{10}$. Nos anos seguintes, o indexante será ajustado tendo em conta as taxas de crescimento económico e de inflação.

Importa salientar a consequência da substituição da remuneração mínima nacional pelo IAS como termo de referência para a indexação das prestações de nível mínimo: representa a renúncia ao princípio da indexação salarial destas prestações, tratando-se, por isso, de uma alteração fundamental. No que se refere às restantes prestações, o novo método de indexação

7 Ver art. $12 .^{\circ}$ e $13 .^{\circ}$ do Decreto-Lei $n .{ }^{\circ} 35 / 2002$, de 19 de Fevereiro.

8 Uma referência à experiência do período entre 2002 e 2004, demonstrativa do impacto reduzido dessa medida, é efectuada adiante. Ver ponto 2.

9 Lei n. ${ }^{\circ} 53-\mathrm{B} / 2006$, de 29 de Dezembro.

10 É de assinalar que o nível do IAS se situa, presentemente, abaixo da remuneração mínima nacional. 
não irá garantir a todos os reformados a manutenção do valor real das pensões. Só as pensões de valor inferior a 1,5 IAS terão o seu valor real garantido. O crescimento nominal das outras pensões poderá não acompanhar a evolução dos preços no consumidor. As pensões superiores a 1,5 IAS e inferiores a 6 IAS só irão manter o seu valor real se o crescimento económico ultrapassar $2 \%$. As pensões superiores a 6 IAS só irão manter o seu valor real se o crescimento económico ultrapassar 3\%.

É de referir, para finalizar, que o Decreto-Lei n. ${ }^{\circ}$ 187/2007, de 10 de Maio, introduz novas regras destinadas a encorajar a manutenção em actividade dos idosos. Por um lado, a antecipação da idade da reforma passa a estar sujeita a uma penalização maior, correspondente a $6 \%$ de redução da pensão estatutária por cada ano de antecipação (em vez de 4,5\%, como anteriormente). Por outro lado, o diploma estabelece incentivos ao prolongamento da vida activa.

\section{Análise Crítica das Medidas Introduzidas}

\subsection{O Efeito das Medidas sobre os Níveis de Rendimentos dos Pensionistas}

As três medidas referidas no ponto anterior convergem no sentido de reduzir o montante das pensões, tendo efeitos a dois níveis: na taxa de substituição, definida no momento de passagem à reforma, e na evolução subsequente do rendimento dos pensionistas.

Em primeiro lugar, a adopção de novas regras para o cálculo da pensão - na sequência da introdução do "factor de sustentabilidade" e da nova fórmula de cálculo - irá reduzir a taxa de substituição do rendimento no momento de passagem à reforma. Importa referir, por um lado, que o "factor de sustentabilidade" é, por definição, um coeficiente de redução da pensão. Por outro lado, a alteração da fórmula de cálculo, fazendo depender o nível das prestações não das remunerações finais mas das remunerações auferidas ao longo de toda a carreira contributiva, produzirá também a redução das pensões. Tendo em conta a tendência para o crescimento real das remunerações ao longo do tempo, a remuneração média dos últimos anos ultrapassa, em geral, a remuneração média de toda a carreira contributiva. Em consequência, o nível das pensões, quando determinado pela nova regra, torna-se inferior para a generalidade dos pensionistas de velhice. A experiência recente é demonstrativa: estima-se que "no período entre 2002 e 2004, cerca de 238060 pensões foram atribuídas, das quais 41713 (aproximadamente 17,52\%) foram definidas com base na totalidade da carreira contributiva [...] garantindo assim aos beneficiários o montante de pensão mais favorável" (European Commission, 2005: 3). De acordo com o texto da lei, acelerar a transição para a nova fórmula de cálculo é desejável porque reforça a natureza contributiva do sistema. A transição é vista como um requisito de justiça. Tal conclusão deriva de uma perspectiva específica sobre a finalidade e os objectivos do sistema de pensões, perfilhada pelos proponentes da reforma, fundamentada numa concepção de justiça particular. É uma concepção baseada num princípio de justiça comutativa, do qual decorre um critério de equidade individual, traduzido no postulado de que cada indivíduo deve receber o equivalente ao seu contributo. Outras perspectivas sobre a finalidade e os objectivos do sistema, fundamentadas em concepções de justiça distributiva, remeterão para critérios de equidade distintos.

Em segundo lugar, os novos mecanismos de ajustamento das prestações, sendo também menos favoráveis que os anteriores, irão afectar negativamente as trajectórias de rendimento no período da reforma. As novas regras não garantem nem a indexação dos níveis mínimos de pensão à remuneração mínima nacional - não estando assegurado que estes cresçam de acordo com evolução geral de rendimentos na sociedade - nem o crescimento nominal das pensões de nível superior a 1,5 IAS ao ritmo da inflação, podendo ocorrer a erosão do respectivo poder de compra.

As novas regras de cálculo da pensão e o novo método de indexação terão inevitavelmente consequências negativas na distribuição do rendimento dos idosos. Assim, a recente reforma pode ser criticada, em primeiro lugar, pelas suas consequências sobre o bem-estar dos 
pensionistas. Desenvolvida com o propósito de assegurar a sustentabilidade financeira do sistema público de pensões, a reforma vai envolver, de facto, a contenção da despesa em pensões. Negligenciaram-se, porém, os efeitos negativos das medidas introduzidas sobre os níveis de rendimentos dos pensionistas. Tal aspecto torna-se particularmente preocupante no caso português, pois os direitos garantidos têm ainda um âmbito material limitado, ao contrário do que se passa em muitos países da Europa. A maioria dos pensionistas não atingiu ainda uma significativa segurança de rendimento na reforma. Na transição para a reforma, ocorrem perdas de rendimento consideráveis, devido à integração passada no mercado de trabalho, caracterizada por baixos níveis remuneratórios e carreiras contributivas incompletas. Ainda assim, quer as regras de cálculo das pensões que antes vigoravam - que definiam a taxa de substituição do rendimento na passagem à reforma - quer as regras de indexação das prestações - que delineavam as dinâmicas de rendimento no período da reforma - eram mais favoráveis do que as agora introduzidas.

\section{O reforço do laço entre contribuições e prestações: um requisito de justiça?}

Antes de prosseguir, merece a pena discutir a ideia de que o reforço da natureza contributiva do sistema constitui um requisito de justiça. Esta ideia, explicitada no texto da lei, associa-se a uma perspectiva particular sobre a finalidade e os objectivos do sistema de pensões, fundamentada numa concepção de justiça específica. Perspectivas diferentes sobre a finalidade e os objectivos do sistema, fundamentadas em concepções de justiça alternativas, apresentam visões distintas dos requisitos de justiça. Importa, pois, evidenciar os pressupostos normativos que estão subjacentes a estas perspectivas.

As pensões de reforma têm uma natureza contributiva pelo facto de se relacionarem com as remunerações anteriormente recebidas e de requererem contribuições prévias. Os esquemas contributivos podem, no entanto, apresentar diferentes configurações no que se refere ao laço estabelecido entre as contribuições individuais de ciclo de vida e as prestações esperadas. As diferentes opções que podem ser tomadas neste domínio traduzem basicamente diferentes perspectivas sobre a desejável presença nos esquemas de dois tipos de redistribuição do rendimento: a redistribuição individual intertemporal e a redistribuição interindividual. Note-se que a extensão da redistribuição incorporada nos esquemas de pensões reflecte, essencialmente, os limites aceites para a esfera da responsabilidade social. Trata-se, pois, de uma escolha normativa, relacionada com os princípios de solidariedade que podem ser realizados na esfera das pensões.

Reconhecem-se diferentes concepções sobre a extensão desejável da redistribuição interindividual nestes esquemas. Um laço forte entre contribuições e prestações permite aos indivíduos receber na reforma um montante de prestações intimamente relacionado com o valor total das contribuições pagas no período de actividade. Num esquema com estas características a redistribuição interindividual do rendimento é praticamente inexistente, pois é excluída ex ante. Pode, porém, ocorrer ex post, em resultado da diferente longevidade dos indivíduos.

Muitos autores argumentam a favor de um laço forte entre contribuições e prestações. Os esquemas de pensões deveriam operar como um mecanismo de transferências individuais intertemporais: a redistribuição do rendimento processar-se-ia entre o período de actividade e o período da reforma. Assim sendo, este mecanismo de transferências deveria ser avaliado segundo um critério de equidade individual. $\mathrm{O}$ valor actual da esperança das prestações totais a receber deveria manter um laço estreito com o valor actual das contribuições efectuadas ao longo da carreira contributiva. A presença de mecanismos de redistribuição interindividual deveria ser excluída destes esquemas.

Apesar de os defensores deste modelo reconhecerem que o sistema desempenha duas funções, a redistributiva e a seguradora, argumentam que a fronteira entre ambas pode ser delimitada com clareza. A redistribuição interpessoal deveria ser realizada apenas através de prestações de natureza não contributiva (universais ou sujeitas a condição de recursos). A 
esfera da responsabilidade social deveria restringir-se a este domínio. As prestações contributivas, por seu turno, situar-se-iam na esfera da responsabilidade individual. Desta forma, as prestações recebidas por um qualquer indivíduo deveriam estar estritamente relacionadas com as suas contribuições prévias. Esta perspectiva fundamenta-se numa concepção ética que atribui valor fundamental ao respeito pelos direitos de propriedade: as contribuições equivalem à constituição de uma poupança individual prévia que legitima a atribuição das prestações futuras.

Há, porém, visões alternativas sobre a natureza do laço entre contribuições e prestações ${ }^{11}$. Outros autores sublinham que os esquemas contributivos não necessitam de manter uma proporcionalidade estreita entre contribuições e prestações. Os esquemas de pensões não são encarados como um mecanismo de poupança forçada que permite aos indivíduos transferir recursos para si mesmos, entre o período de actividade e o período da reforma. Apesar de as prestações serem definidas numa base comutativa - pois relacionam-se com o estatuto laboral, o seu propósito é substituir remunerações cessantes e têm como requisito de atribuição a existência de contribuições prévias - o seu valor total esperado não terá de manter uma proporcionalidade estrita com o montante das contribuições efectuadas. Num esquema público podem estar presentes mecanismos de redistribuição interindividual. A função redistributiva pode ser desempenhada não apenas pela componente não contributiva da estrutura das prestações mas também pela sua componente contributiva. Assim, pode estar envolvido um certo grau de redistribuição nos esquemas contributivos. A redistribuição pode ocorrer ex post, em resultado das diferenças de longevidade individuais ou ser especificada ex ante. De facto, estes mecanismos incluem frequentemente regras que estabelecem níveis mínimos de pensões ou normas que garantem taxas de substituição superiores para os rendimentos mais baixos. É de referir, também, que a regra de cálculo, por vezes, enfraquece deliberadamente o laço entre as contribuições pagas ao longo de toda a carreira e as prestações recebidas. Quando o objectivo é garantir um certo nível de bem-estar, o valor das pensões pode ser calculado com base nas remunerações recebidas nos últimos anos de actividade e não a partir das remunerações da totalidade da carreira contributiva.

A configuração de um esquema contributivo, em particular no que diz respeito à natureza do laço estabelecido entre contribuições e prestações, pode, pois, ser diferenciada. Pressupostos normativos distintos irão condicionar a escolha de diferentes configurações para estes esquemas. Se a primeira concepção de justiça analisada confere um valor fundamental ao respeito pelos direitos de propriedade (pois, segundo ela, a atribuição das prestações futuras é legitimada pela constituição de uma poupança individual prévia), uma concepção ética de inspiração igualitarista que privilegie outros valores - como a liberdade, entendida não apenas na sua formulação negativa mas na sua faceta positiva ${ }^{12}$, ou a realização das potencialidades humanas, etc. - pode ser mais favorável à aceitação de mecanismos de redistribuição interindividuais. Privilegiar outros princípios e valores pode conduzir à formulação de objectivos alternativos - como, por exemplo, realizar uma certa paridade de níveis de vida entre pensionistas e activos - e outras configurações para o sistema de pensões.

\subsection{Uma Crítica Metodológica}

A reforma em análise pode também ser objecto de crítica metodológica por não definir objectivos para o nível das prestações, que se torna a variável de ajustamento. Uma política

11 Ver Thompson (1983). Para uma discussão da base normativa das pensões, ver Gillion et al. (2000). 120 conceito de liberdade pode ter duas formulações, uma negativa - entendida como ausência de restrição - e outra positiva. Na sua faceta positiva, a liberdade é entendida como capacidade de agir e de realizar os seus propósitos fundamentais ou, na terminologia de Sen, como capacidade de escolha do modo de vida que os indivíduos valorizam. O pensamento liberal tem subjacente uma definição negativa de liberdade. O papel do Estado deve ser reduzido na medida em que impõe limites à acção individual. Os críticos do liberalismo, por seu turno, argumentam que a liberdade positiva é um produto da organização social e que a sua promoção requer a intervenção pública. 
social coerente neste domínio requer uma especificação clara dos objectivos sociais a atingir. Ora, as pensões de reforma (de natureza contributiva) são mecanismos de garantia de substituição do rendimento de actividade. Por isso, importará formular objectivos em dois domínios: a taxa de substituição do rendimento, no momento de passagem à reforma, e a indexação das prestações ao longo do tempo.

No texto da lei ${ }^{13}$, porém, não há qualquer referência aos objectivos a atingir em matéria de rendimento garantido aos pensionistas nem às consequências, a esse nível, das medidas adoptadas. Em 2006, o Ministério da Solidariedade e Segurança Social publicou um documento em que revela as linhas estratégicas da reforma ${ }^{14}$, onde, também, nenhuma referência é efectuada aos objectivos referidos. No final desse ano, o Ministério das Finanças e da Administração Pública, no Relatório do Orçamento de Estado para $2007^{15}$, irá divulgar as estimativas dos efeitos da reforma no que se refere à redução de prestações. No Anexo III desse documento, é efectuada uma análise da sustentabilidade da segurança social. As reformas programadas são consideradas necessárias para promover a redução futura da despesa em pensões e apresentadas como solução para garantir a sustentabilidade financeira do sistema público.

De acordo com as projecções do governo, a despesa no conjunto do subsistema previdencial deveria crescer cerca de $2.4 \%$ do PIB nos próximos vinte anos. Em 2006, o subsistema apresentava ainda um excedente mas, em 2025, iria apresentar um défice de $-1,9 \%$ do PIB. A despesa em pensões (velhice, invalidez, sobrevivência) iria crescer de 5,5\% para 7,9\% do PIB. As pensões de velhice deveriam crescer de 4\% do PIB, em 2006, para 6,3\%, em 2025. De acordo com as projecções oficiais, as novas regras permitem a redução futura da despesa em pensões e do crescimento real da pensão média (Gráfico 1, em Anexo). Estes efeitos são considerados positivos na perspectiva do Orçamento de Estado.

Esta metodologia, porém, na perspectiva da política social, revela-se inconsistente. O objectivo explícito da reforma é equilibrar financeiramente o subsistema previdencial. De modo a garantir a realização de tal propósito, o nível das prestações torna-se a variável de ajustamento.

Por um lado, é de salientar que, na óptica da política social, o equilíbrio financeiro a longo prazo do subsistema previdencial deve ser perspectivado como "a restrição" a respeitar e não como "o objectivo primordial a atingir". Por outro lado, uma metodologia coerente de definição de medidas de política neste domínio exige a especificação clara dos objectivos a atingir no que se refere à substituição de rendimento na reforma. A função social do sistema consiste em fornecer tal garantia. Por isso, na perspectiva da política social, o nível de rendimento assegurado na reforma deve ser considerado variável objectivo. Consequentemente, não deverá ser tomado como um aspecto residual numa política traçada com o propósito de assegurar a sustentabilidade financeira do sistema. Os objectivos a atingir no que se refere à garantia de rendimento na reforma deverão ser tratados, sempre, como princípios fundamentais orientadores de qualquer reforma. Tais objectivos devem ser claramente formulados a priori e, do meu ponto de vista, tomados como ponto de partida.

Importa referir ainda que, conforme se verá no ponto seguinte, a política de redução da despesa em pensões não constitui a única via possível para assegurar o equilíbrio financeiro do subsistema previdencial. É possível realizar tal propósito, recorrendo a outras variáveis de ajustamento.

\section{Estratégias Alternativas para Lidar com o Envelhecimento Demográfico}

Neste ponto efectua-se uma referência breve às direcções alternativas que as políticas de pensões podem seguir para enfrentar a longevidade crescente. A discussão das alternativas é 
efectuada a partir de uma óptica macroeconómica ${ }^{16}$. Para desenvolver a análise, importa efectuar uma alusão prévia à função económica das pensões, distinguindo a perspectiva dos indivíduos da perspectiva agregada. A partir da reflexão subsequente conclui-se que o rumo seguido em Portugal não constituía a única solução possível, havendo diversas formas de ajustar os esquemas de pensões neste contexto.

\subsection{A Função Económica das Pensões}

\section{A Perspectiva dos Indivíduos}

Na perspectiva dos indivíduos, a função económica das pensões consiste em assegurar a afectação intertemporal do consumo, ou seja, transferir consumo do período activo para o período da reforma. A obrigação de contribuir para um esquema de pensões reduz o consumo no período de actividade, com o propósito de garantir o consumo no período da reforma.

Só há duas formas de transferir consumo no tempo: armazenar produção corrente para utilização futura ou trocar a produção corrente por um direito à produção futura (Barr, 2004). Só a segunda é exequível. Para tal, podem ser seguidos dois métodos: poupando uma parte do salário, o trabalhador pode adquirir activos que irão ser trocados, no período da reforma, por bens produzidos pelas gerações activas; ou obtendo uma promessa (dos filhos, do empregador, do Estado) de atribuição futura (no seu período da reforma) de bens produzidos pela população activa. Os dois modos essenciais de organizar as pensões aproximam-se destes métodos: a capitalização baseia-se na acumulação de activos financeiros e a repartição numa promessa.

\section{A Perspectiva Agregada}

\section{a) O custo económico da população reformada na perspectiva macroeconómica}

Na perspectiva da sociedade no seu conjunto, o custo económico da população reformada equivale à fracção do rendimento total utilizada para seu consumo (Thompson, 1998). Os bens e serviços consumidos pela população reformada são, assim, a medida do seu custo económico.

Os rendimentos gerados no processo produtivo remuneram os factores de produção, sendo esses rendimentos utilizados, em parte ou na totalidade, para consumir os bens e serviços produzidos no período. Tendo em consideração que os reformados se encontram em situação de inactividade, importa questionar como pode o seu consumo ser assegurado. Os bens e serviços por estes consumidos são produzidos em períodos próximos daquele em que são consumidos. Contudo, o consumo dos reformados não se pode basear no rendimento de trabalho, tendo de assentar noutros recursos. Por um lado, se os reformados forem detentores de capital, uma parte do seu consumo pode ser resultante da remuneração do capital. Por outro lado, o seu consumo pode resultar de transferências de recursos realizadas por aqueles que continuam a trabalhar. Este tipo de transferências representa a parte mais expressiva do conjunto dos recursos dos reformados ${ }^{17}$.

As sociedades utilizam combinações diferentes de três mecanismos para realizar as transferências de poder de compra da população em idade activa para os reformados: transferências informais intrafamiliares; regimes de contribuições obrigatórias, que incidem sobre o rendimento dos activos, destinando-se a financiar as prestações pagas aos reformados; transacções de activos físicos ou financeiros entre a população reformada (vendedora) e a

16 Neste ponto segue-se de perto a análise desenvolvida por Barr (2004). Sobre a economia das pensões, ver Thompson (1998), Barr (2004), Barr (2006), Barr e Diamond (2006).

17 Os rendimentos de capital suportam apenas minoritariamente o consumo da população reformada. Dois factores explicam este facto: o reinvestimento dos rendimentos de capital, por um lado, e a forma como a propriedade do capital se encontra distribuída entre os membros da sociedade, por outro. Ver Thompson (1998: 38). 
população activa (compradora). Note-se que um sistema de capitalização pode ser visto como mecanismo do último tipo. A população em idade activa concebe tal mecanismo como um modo de formação de poupança para a reforma quando, de facto, corresponde à aquisição de activos.

Os três mecanismos suscitam uma redução voluntária ou involuntária do consumo da população activa (inferior à totalidade do rendimento gerado no processo produtivo) para possibilitar o consumo dos reformados (superior ao respectivo rendimento com origem no processo de produção).

\section{b) Os métodos de organização de direitos sobre o produto futuro}

A capitalização é um método de acumulação de activos financeiros cujo rendimento permite adquirir bens numa data posterior. As contribuições para estes esquemas são investidas em activos financeiros, sendo o respectivo retorno creditado no fundo de pensões. As reservas constituídas nos fundos de capitalização são utilizadas para fazer face às responsabilidades, isto é, para efectuar o pagamento das prestações.

Os esquemas de repartição são desenvolvidos pelo Estado e têm natureza legal. Tais esquemas operam transferências instantâneas entre trabalhadores e pensionistas, pois as prestações pagas aos reformados, em cada período, provêm das contribuições efectuadas pelos trabalhadores no mesmo período. Na perspectiva individual, o direito à pensão baseia-se num contrato implícito: o pagamento de cotizações no presente confere o direito ao recebimento de prestações no futuro. Porém, numa perspectiva macroeconómica, o Estado está apenas a promover transferências correntes de um grupo da população para outro.

O argumento de que os esquemas de capitalização protegem melhor os indivíduos do que os esquemas de repartição em relação às alterações demográficas não foi comprovado ${ }^{18}$. Essa ideia constitui, segundo Barr (2004: 194), um exemplo ilustrativo do sofisma da composição. $\mathrm{Na}$ perspectiva individual, um esquema de pensões efectua uma transferência intertemporal de consumo. Porém, tal transferência não é possível à escala social: o consumo dos reformados provém sempre, e em última instância, dos bens produzidos pela futura geração de trabalhadores. De um ponto de vista agregado, a função económica dos esquemas de pensões consiste em repartir o produto total de um período entre trabalhadores e reformados - 0 consumo dos primeiros é reduzido para permitir o consumo dos segundos. A repartição, porém, evidencia de forma inequívoca que as pensões envolvem recursos correntes.

Numa visão macroeconómica, a variável fundamental é o produto. O objectivo dos sistemas de pensões é permitir aos reformados continuar a consumir no período de inactividade. Como os bens e serviços por estes consumidos são produzidos nesse período pelos activos, o produto futuro é variável essencial, pois dele provirá o consumo dos reformados futuros. A repartição e a capitalização são apenas mecanismos financeiros de organização de direitos sobre o produto futuro ${ }^{19}$.

\subsection{Políticas para Enfrentar o Envelhecimento Populacional}

De um ponto de vista macroeconómico, o custo económico da população reformada é equivalente à fracção do rendimento total utilizada para seu consumo, $\mathrm{C}_{\mathrm{r}} / \mathrm{Y}$. Deste modo, a longevidade crescente tende a elevar este quociente. Para enfrentar o aumento da esperança de vida, identificam-se dois tipos de políticas: políticas do lado da procura (com efeitos no numerador da expressão) e políticas do lado da oferta de bens e serviços (com efeitos no denominador). 
No que se refere às políticas do lado da procura, a repartição da despesa em bens de consumo, entre activos e reformados, pode ser modificada na sequência do aumento das contribuições ou da redução das prestações. No primeiro caso, o ónus do ajustamento recai exclusivamente sobre os trabalhadores. No segundo caso, o ónus do ajustamento incide na íntegra sobre os reformados. É ainda possível recorrer a uma terceira solução: o aumento da idade da reforma. Esta medida pode potenciar dois efeitos simultâneos: o aumento do número de trabalhadores e a redução do número de reformados, dependendo a sua viabilidade do contexto do mercado de trabalho. A ser concretizada, tal via permite a contenção da despesa e, ao mesmo tempo, evita a redução dos níveis de vida dos pensionistas. O prolongamento da vida activa pode apresentar-se como uma alternativa à contenção do consumo. Assim, do lado da procura, configuram-se diversas soluções: reduzir as pensões, aumentar as contribuições, ajustar a idade da reforma ou uma combinação das três medidas. Como Barr (2006: 13) observa, "a um dado nível de produto nacional, estas três políticas - reduzir pensões, elevar contribuições ou aumentar a idade da reforma - são apenas mecanismos para dividir o output de diferentes formas entre trabalhadores e pensionistas".

É também possível desenvolver medidas do lado da oferta. As políticas que promovem o crescimento económico contribuem para atenuar a pressão decorrente do envelhecimento populacional, pois permitem o crescimento do consumo per capita. $\mathrm{O}$ acréscimo do produto pode ser atingido através de duas estratégias fundamentais: o aumento do produto por trabalhador ou o aumento do número de trabalhadores. A elevação do produto por trabalhador pode resultar de acréscimos na quantidade e qualidade do capital e da melhoria da qualidade do trabalho. $\mathrm{O}$ acréscimo do número de trabalhadores pode ser atingido através da redução do desemprego, elevando a idade da reforma, aumentando a participação feminina no mercado de trabalho ou através da imigração.

No tocante às estratégias para enfrentar o envelhecimento demográfico, dado que o produto é uma variável central, as políticas que promovem o crescimento são decisivas na resposta à questão (Barr, 2004). Uma regulação macroeconómica mais favorável ao crescimento e ao emprego terá um importante papel nessa resposta.

Face ao exposto, torna-se pertinente o confronto das modalidades de financiamento das pensões, na medida em que estas podem, eventualmente, influenciar o nível de produção. Os partidários da capitalização argumentam que esta seria superior à repartição por potenciar o crescimento económico. A vantagem da capitalização adviria do facto de suscitar acréscimo de poupança, que se iria traduzir em acréscimo do investimento produtivo e, por essa via, do produto. No entanto, os estudos teóricos e empíricos desenvolvidos sobre a matéria são inconclusivos e controversos. Carece de demonstração que a capitalização seja um método eficiente para promover o investimento produtivo e, por essa via, o crescimento económico ${ }^{20}$. Em primeiro lugar, não é certo que a capitalização eleve a poupança, pois um acréscimo da poupança obrigatória pode ser contrabalançado pela redução da poupança voluntária. Em segundo lugar, mesmo que se verifique um aumento da poupança, não está comprovado que este envolva um aumento do investimento produtivo. Por um lado, não é certo que a poupança se converta automaticamente em investimento produtivo. Por outro lado, se o ritmo de crescimento económico for lento, a elevação da poupança poderá ter efeitos depressivos sobre o nível de actividade económica. Finalmente, o aumento do investimento produtivo pode não ter um efeito significativo sobre o output.

A capitalização, enquanto mecanismo destinado a promover o crescimento económico, opera de forma indirecta e com resultados indeterminados. Assim sendo, Barr (2004) recomenda que se considerem prioritariamente as políticas que promovem directamente o crescimento do produto.

Conclui-se que podem ser desenvolvidas diversas soluções para enfrentar os problemas futuros suscitados pelo envelhecimento demográfico. Havendo a possibilidade de recorrer a políticas do 
lado da procura e a políticas do lado da oferta, na discussão sobre as reformas não se efectuou qualquer referência às segundas. No que respeita às políticas do lado da procura, a possibilidade de elevar as contribuições não foi sequer considerada ${ }^{21}$ e excluiu-se o aumento da idade da reforma ${ }^{22}$.

O governo português decidiu seguir uma única via: reduzir as pensões, fazendo com que os pensionistas suportem na íntegra o encargo do ajustamento. O rumo político seguido afigura-se criticável, do meu ponto de vista, dada a especificidade da situação dos pensionistas no país. Como é sabido, o seu nível de vida relativo ${ }^{23}$ é significativamente inferior ao da população em geral e o seu risco de pobreza bastante superior ${ }^{24}$. Neste contexto, a opção anterior afigura-se particularmente gravosa por colocar o encargo do ajustamento exclusivamente sobre os pensionistas.

\section{A estratégia de reduzir pensões}

É de mencionar que a política de contenção da despesa em pensões ocorre em simultâneo com a introdução de novos mecanismos dirigidos aos pensionistas mais pobres, como uma prestação especial, sujeita a condição de recursos, designada "complemento solidário para idosos"25, destinada a atenuar situações de pobreza.

Importa salientar que a estratégia de reduzir pensões, em simultâneo com o reconhecimento explícito de que a prevenção da pobreza entre os idosos é prioridade política, representa um ponto de viragem na filosofia do sistema. Reflecte uma mudança radical de perspectiva, pois a intervenção pública fica focalizada num único objectivo, o de prevenir a pobreza, negligenciando o outro objectivo fundamental dos sistemas de pensões, i.e. a salvaguarda dos níveis de vida no período da reforma.

21 A possibilidade de elevar as contribuições para o sistema foi liminarmente excluída. Dois argumentos essenciais, não validados teórica ou empiricamente, sustentam o dogma, hoje generalizado, da impossibilidade de aumento das contribuições. Por um lado, a elevação das contribuições representa um aumento do custo do trabalho, o que conduz à perda de competitividade e desencadeia uma redução da rendibilidade das empresas. Desta forma, tal solução seria prejudicial ao emprego e, em última análise, aos próprios sistemas de pensões. Este argumento é discutido em Thompson (1998). Por outro lado, a elevação das contribuições iria reduzir a poupança e, em consequência, o investimento produtivo e a produção. A estes dois argumentos, adiciona-se, por vezes, um terceiro, o da resistência política da população ao aumento das contribuições. Sobre o dogma da impossibilidade de aumentar as contribuições ver Math (2001).

22 É de observar que, no actual contexto de crescimento e emprego, seria dificilmente defensável que a idade da reforma fosse tomada como variável de ajustamento.

23 Ver, por exemplo, European Commission (2006). De acordo com os dados aí publicados, em muitos países, a posição relativa de rendimento dos idosos é próxima da média da população em geral, ou mesmo superior. Em Portugal, a relação entre o rendimento mediano equivalente dos idosos e das coortes mais jovens é apenas de $76 \%$.

$24 \mathrm{O}$ risco de pobreza é medido em termos relativos e definido como a percentagem de indivíduos com rendimento disponível equivalente inferior a um limiar de $60 \%$ da mediana nacional. A incidência da pobreza entre os indivíduos com mais de 65 anos ultrapassa os $29 \%$, número substancialmente superior ao da população em geral, que ronda $19 \%$.

25 Decreto-Lei n. ${ }^{\circ}$ 232/2005, de 29 de Dezembro. No preâmbulo deste diploma, lê-se: "[o] complemento solidário para idosos traduz uma verdadeira ruptura com a anterior política de mínimos sociais para idosos, através de uma aposta na concentração de recursos disponíveis nos estratos da população idosa com menores rendimentos, na atenuação das situações de maior carência [...] e na solidariedade familiar". O texto da lei afirma estas prestações como um elemento de ruptura que vem reconfigurar a política de mínimos sociais. Discordo profundamente da lógica subjacente a esta medida. As prestações sujeitas a condições de recursos deveriam, na minha perspectiva, ter um carácter residual, pela sua natureza estigmatizante, no âmbito de um sistema de garantia de níveis mínimos de rendimento. Ora, de acordo com o texto do diploma, a introdução desta prestação poderá vir a pôr em causa o aumento generalizado do valor das pensões mínimas. A concretizar-se este intuito, operar-se-á, a meu ver, um processo de regressão social inaceitável. 
Este é um objectivo fundamental do sistema, ou seja, assegurar que as pessoas possam manter na reforma, na medida do possível, os níveis de vida alcançados no período de actividade. Porém, o facto de se admitir ao mesmo tempo o decréscimo programado das pensões médias, por via da redução das taxas de substituição para a maioria dos reformados, e a desindexação dos rendimentos dos pensionistas da evolução geral de rendimentos e preços, com a consequente redução do seu nível de vida relativo, comprova que este objectivo foi negligenciado.

A reforma é inspirada por uma visão dominante, porém contestável. "A protecção oferecida pelo Estado de bem-estar é frequentemente discutida em termos de redução de pobreza, mas esta é uma visão muito limitada das suas funções. A redução da pobreza é um importante objectivo, mas é só um dos propósitos de programas como as pensões de reforma [...]" (Atkinson, 1999: 5). No mesmo sentido, a propósito do título, aparentemente paradoxal, do seu artigo "The Welfare State versus the Relief of Poverty", afirma Barry (1990: 73): "[N]um Estado de bem-estar bem organizado quase toda a tarefa de reduzir a pobreza será efectuada através de políticas cujos objectivos e racionalidades são bastante diferentes. [...] Se o Estado de bem-estar tiver de ser identificado com um objectivo, será o da manutenção de rendimento e não o da redução da pobreza".

\section{Uma Metodologia Alternativa}

Concluiu-se que os objectivos a atingir em matéria de garantia de rendimento na reforma deverão ser tratados, sempre, como princípios fundamentais orientadores da arquitectura dos esquemas de pensões e que tais objectivos devem ser claramente formulados a priori. Em conformidade com este princípio, propõe-se, no presente tópico, uma metodologia alternativa para configurar os esquemas de pensões que principia pela definição de objectivos para os níveis de rendimento garantidos na reforma. Nesta matéria, o objectivo social estabelecido pode ser muito diferenciado: desde a garantia de níveis mínimos de pensões até à garantia de manutenção dos níveis de vida anteriormente atingidos.

A definição dos objectivos é uma escolha fundamental que remete, evidentemente, para o domínio normativo. Importa, por isso, explicitar a priori um conjunto de pressupostos normativos assumidos. Seguidamente, discute-se a forma como os objectivos gerais se podem traduzir em critérios mais específicos, que representam uma tradução concreta dos objectivos sociais a atingir no domínio dos rendimentos garantidos.

\subsection{Os Objectivos das Políticas e a Garantia de Rendimento na Reforma}

As pensões de reforma podem ter natureza contributiva ou não contributiva. Em geral, as pensões não contributivas são garantidas a todos os cidadãos, na idade da reforma (prestações universais ou sujeitas a condições de recursos), com o objectivo de evitar ou reduzir situações de pobreza. As pensões de natureza contributiva são garantidas a todos os trabalhadores, a partir do momento em que estes atingem a idade legal da reforma, com o objectivo de substituir o rendimento de actividade. $O$ direito às prestações decorre da realização de contribuições prévias, durante um período relevante, estando o montante da pensão dependente das remunerações anteriores e do número de anos de contribuições. No presente artigo examina-se apenas este tipo de prestações.

\section{Os objectivos das pensões de natureza contributiva}

No tocante às prestações de natureza contributiva, garantidas a todos os trabalhadores no momento da reforma, os objectivos das políticas públicas podem variar desde a garantia de níveis mínimos até à salvaguarda dos níveis de vida previamente atingidos. Em consequência, estes esquemas podem ter configurações distintas relacionadas com diferentes finalidades das políticas. Frequentemente, garantem níveis mínimos de pensões aos trabalhadores que apresentam um período mínimo de contribuições, com o propósito de prevenir situações de 
pobreza. Este, porém, pode não ser o único objectivo. Em muitos casos, os sistemas têm um âmbito mais alargado, garantindo níveis de pensões calculados com base nos níveis de remunerações anteriores e que são significativamente superiores aos níveis mínimos de rendimento destinados a evitar a pobreza. Tais níveis de prestações são garantidos para permitir preservar, na medida do possível, os níveis de vida anteriormente atingidos ${ }^{26}$.

\subsection{Uma Visão Normativa sobre a Garantia de Rendimento na Reforma}

Antes de apresentar a visão defendida no tocante à garantia de rendimento na reforma, importa clarificar a perspectiva normativa assumida.

Em primeiro lugar, é conveniente explicitar a visão perfilhada no que se refere à configuração dos esquemas contributivos. No ponto 2.1 efectuou-se uma alusão breve às diferentes configurações que estes esquemas podem assumir, em particular no que diz respeito à natureza do laço estabelecido entre contribuições e prestações. A opção entre modelos alternativos é condicionada pelos princípios e valores privilegiados. Perfilho uma visão que se afasta da concepção que advoga o estabelecimento de um laço forte entre contribuições e prestações.

Segundo essa perspectiva, o sistema de pensões desempenha duas funções, a redistributiva e a seguradora, podendo a fronteira entre ambas pode ser delimitada com clareza. A redistribuição interpessoal deveria ser realizada apenas através de prestações não contributivas, que caberiam na esfera da responsabilidade social e seriam legitimadas por uma ideia de necessidade. Nos esquemas contributivos, por seu turno, a redistribuição deveria estar ausente. Estes são encarados como mecanismos de transferência de recursos do indivíduo para si mesmo, entre duas fases do "ciclo de vida", cabendo no âmbito da responsabilidade individual. A visão descrita aproxima-se do pensamento liberal. A atribuição das prestações futuras seria legitimada pela constituição de uma poupança individual prévia (as contribuições realizadas). Para respeitar direitos de propriedade, importa manter um laço estreito entre as prestações e as contribuições.

A concepção ética que perfilho atribui um valor fundamental à igualdade de liberdade positiva. Em consequência, o meu pensamento inscreve-se numa corrente mais favorável à inclusão nestes esquemas de mecanismos de redistribuição interindividual. A redistribuição pode ser desempenhada pela componente não contributiva da estrutura das prestações ou pela componente contributiva. As prestações de natureza não contributiva (universais ou sujeitas a condições de recursos) destinam-se a fazer face a situações de necessidade. Os esquemas contributivos, por seu turno, podem também ter objectivos redistributivos, integrando mecanismos como, por exemplo, as regras que definem níveis mínimos de pensões ou a garantia de taxas de substituição superiores para os rendimentos mais baixos. Nesta lógica, não é necessário que o laço estabelecido entre as contribuições realizadas e as prestações recebidas, a nível individual seja estrito. Quando o objectivo das políticas consiste em assegurar um certo nível de bem-estar, a regra de cálculo pode enfraquecer deliberadamente esse laço. Tal acontece, por exemplo, quando o valor das pensões é calculado com base nas remunerações recebidas nos últimos anos de actividade e não a partir das remunerações da totalidade da carreira contributiva.

Em segundo lugar, na minha perspectiva, a justiça entre contemporâneos deve ser considerada uma preocupação ética fundamental, sendo fulcral promover a realização de uma certa paridade de níveis de vida entre pensionistas e activos. Assim, a configuração dos esquemas

26 Verifica-se hoje uma reversão de tendência na fixação de objectivos para as políticas de pensões em relação ao movimento observado, a partir dos anos sessenta do século XX, em muitos países europeus. Na década referida, operou-se uma mudança radical nos objectivos das políticas de pensões: passou-se da garantia de níveis de vida mínimos para a salvaguarda dos níveis de vida prévios. Este movimento ocorreu primeiro na Alemanha e Suécia sendo seguido, nos anos sessenta e setenta, por outros países desenvolvidos. Foi o resultado de uma política deliberada destinada a melhorar os níveis de vida dos pensionistas. $\mathrm{Na}$ sequência dessa política, em muitos países europeus e também no Canadá, nos Estados Unidos e no Japão, a diferença entre os níveis de vida médios dos pensionistas e da restante população reduziu-se significativamente. Ver Rein e Turner (1999) e Myles (2002). 
de pensões deverá ser delineada em conformidade. No que respeita às finalidades e objectivos das políticas, considero essencial não renunciar à prossecução dos dois objectivos primordiais das pensões: a prevenção da pobreza e a salvaguarda dos níveis de vida no período da reforma. Como se referiu anteriormente, a reforma recente focaliza a intervenção do Estado quase exclusivamente no primeiro objectivo, negligenciando o segundo. A concretizar-se tal tendência, reduzir-se-á significativamente o âmbito da acção pública neste domínio. Com efeito, renuncia-se ao objectivo fundamental de assegurar a manutenção dos níveis de vida no período da reforma, de cuja prossecução depende a possibilidade de realizar a paridade entre os níveis médios de vida dos reformados e dos seus contemporâneos.

Explicitada a posição assumida relativamente aos aspectos normativos referidos, importará analisar as consequências desta visão no tocante à formulação dos objectivos a atingir em matéria de garantia de rendimento na reforma. Dois domínios fundamentais requerem ponderação: a substituição de rendimento que ocorre no momento de cessação de actividade e a indexação do rendimento durante o período da reforma.

Em consonância com perspectiva explicitada, os rendimentos dos pensionistas, a cada momento, devem ser avaliados em termos relativos, tendo em consideração os níveis de rendimento correntes na sociedade a cada momento. $\mathrm{Na}$ transição para a reforma, os pensionistas podem sofrer uma perda de rendimento significativa se as pensões médias forem muito inferiores aos níveis remuneratórios anteriores. Consequentemente, o rendimento da pensão pode vir a situar-se significativamente abaixo do nível remuneratório anteriormente atingido e dos níveis médios de rendimento correntes na sociedade nesse momento. A dinâmica de rendimento no período da reforma, por seu turno, irá depender fundamentalmente dos mecanismos de indexação das prestações. O rendimento relativo dos pensionistas pode continuar a diminuir neste período. Assim, a redução da posição relativa de rendimento observada na transição para a reforma pode manter-se ou intensificar-se no período da reforma ${ }^{27}$.

Devido à redução do rendimento que ocorre na transição para a reforma ou à forma como as pensões são indexadas posteriormente, os pensionistas podem ter um nível de vida relativamente baixo. Neste caso, a sociedade pode enfrentar um problema de justiça entre contemporâneos. Tal situação virá a ocorrer quando as prestações não são suficientes para evitar a pobreza na velhice ou quando os rendimentos dos pensionistas se situarem significativamente abaixo dos níveis correntes na sociedade. Uma maior incidência de pobreza entre os idosos ou uma significativa disparidade de rendimento dos pensionistas relativamente à população no seu conjunto são, do meu ponto de vista, eticamente relevantes. A justiça entre contemporâneos ${ }^{28}$ deverá ser considerada uma preocupação ética fundamental.

Na sequência da adopção desta perspectiva, a definição de objectivos a atingir em matéria de garantia de rendimento - quer para a substituição de rendimento que ocorre no momento de cessação de actividade, quer para a indexação de rendimento ao longo do período da reforma - deverá ser orientada por critérios de natureza relativa.

$\mathrm{Na}$ transição para a reforma, importa ter em conta, em primeiro lugar, que o objectivo das pensões consiste em substituir o rendimento de actividade cessante ${ }^{29}$. Assim, um primeiro ponto

27 É de sublinhar que o nível de vida relativo dos pensionistas, em cada momento, reflecte, em geral, não uma situação transitória mas permanente. Por um lado, os rendimentos dos pensionistas são determinados pelas remunerações prévias. A distribuição das pensões reproduz em regra o padrão de desigualdade da distribuição das remunerações. Por outro lado, no período da reforma, os níveis das pensões dependem das regras de indexação mas têm, em geral, uma correlação estreita com os níveis anteriores de pensões. 28 Sobre desigualdades entre contemporâneos, ver Fleurbaey e Michel (1992) e Fleurbaey (2002).

29 Para os pensionistas de rendimentos mais baixos, as prestações garantidas ao longo do tempo deverão permitir, no mínimo, assegurar a sua participação social. O rendimento que permite a participação social é, obviamente, dinâmico e relativo, pois condicionado pelos níveis de rendimento correntes na sociedade, ao longo do tempo. Esta matéria exige análise conceptual específica, que não cabe no âmbito do presente artigo. O tópico é desenvolvido, por exemplo, em Atkinson (1995). 
de referência deverá ser constituído pelas remunerações anteriores. Admitindo que o objectivo da política é permitir aos pensionistas manter, na medida do possível, os níveis de vida anteriores, as últimas remunerações devem ser tomadas como referência. Em segundo lugar, de acordo com a perspectiva normativa defendida, os objectivos a atingir deverão ser formulados com base num critério relativo e, em consequência, o segundo ponto de referência deverá corresponder ao nível médio de rendimento corrente na sociedade, no momento. $\mathrm{O}$ objectivo a atingir na transição para a reforma, segundo a perspectiva agora explicitada, deveria consistir em evitar uma queda substancial no nível de vida. Em termos concretos, a substituição do rendimento individual, que ocorre nesse momento, deveria garantir pensões médias não muito inferiores ao valor médio das últimas remunerações. Desta forma, os pensionistas conseguiriam manter, na medida do possível, os níveis de vida anteriores. Se a primeira pensão, em média, não se situar muito abaixo do nível remuneratório anterior, cumprir-se-á a condição necessária para assegurar também que o rendimento médio dos pensionistas não se torna significativamente inferior ao rendimento médio corrente na sociedade.

No período da reforma, como se referiu, a dinâmica de rendimento dos pensionistas depende fundamentalmente dos mecanismos de indexação. Estes são o seu principal factor explicativo. Assim, as regras de ajustamento dos níveis de prestações constituem um mecanismo fundamental para evitar uma incidência crescente da pobreza dos idosos e, também, para garantir que o rendimento médio dos pensionistas não se distancia significativamente do rendimento médio corrente na sociedade a cada momento. Para tal, importará que a revalorização das prestações se alinhe não só com a evolução dos preços mas com a evolução geral dos rendimentos.

\subsection{Breve Referência à Condicionante Financeira}

Não estando no âmbito do presente artigo proceder a uma discussão aprofundada da sustentabilidade financeira futura do sistema público de pensões, justifica-se, porém, uma alusão breve à condicionante financeira.

Uma das principais críticas dirigidas à reforma relaciona-se com o facto de realizar o equilíbrio financeiro futuro do subsistema previdencial através da contenção da despesa em pensões. Ora, a opção tomada não constituía, porém, a única solução para realizar o equilíbrio financeiro do sistema. Se a parte das despesas públicas em pensões tende a aumentar mais rapidamente que o PIB, há diversas formas de promover o equilíbrio financeiro do sistema. Esse propósito pode ser assegurado por via da contenção das despesas, por via do aumento das receitas ou através de uma combinação dos dois tipos de medidas.

Há um conjunto de políticas que podem ser promovidas no lado da despesa. Uma solução possível foi a escolhida pelos mentores da reforma: reduzir a despesa, presente ou futura, em pensões directamente. Esta via coloca o ónus do ajustamento sobre os reformados. Uma outra solução passa por permitir uma despesa futura em pensões superior, sendo esta compensada por uma redução de outras componentes da despesa pública ${ }^{30}$. Uma terceira hipótese consistiria em acumular recursos no presente para fazer face ao previsível aumento da despesa futura em pensões e, assim, reduzir o esforço contributivo futuro ${ }^{31}$.

O equilíbrio financeiro presente e futuro, porém, pode realizar-se não apenas por via da contenção das despesas mas também através do aumento das receitas potenciado, por exemplo, pela elevação das contribuições sociais. No entanto, a hipótese de tomar as contribuições como variável de ajustamento não foi sequer ventilada. Generaliza-se, hoje, a posição dogmática segundo a qual é impossível aumentar as contribuições. 
De igual modo, o aumento da idade da reforma tem efeitos positivos numa perspectiva orçamental: contribui, em simultâneo, para elevar as receitas e diminuir as despesas do subsistema. Para que a adopção desta medida seja viável, porém, é necessário reunir um conjunto de condições no mercado de trabalho. Em particular, a idade da reforma só deverá ser tomada como variável de ajustamento se o rendimento estiver próximo do nível de pleno emprego.

Também uma regulação macroeconómica mais favorável ao crescimento e ao emprego tem impacto positivo no equilíbrio financeiro do sistema. Em particular, o aumento da população activa empregada (resultante da redução do desemprego, do aumento da participação feminina no mercado de trabalho ou da imigração) contribui directamente para o equilíbrio financeiro dos esquemas da repartição, por via da elevação das receitas de contribuições.

Assim, o ponto de vista defendido pode ser sumariado como se segue. A reforma teve por objectivo primordial assegurar o equilíbrio financeiro do sistema público de pensões, realizado através da contenção da despesa em pensões, mas esta não era a única alternativa possível. $O$ nível das prestações foi considerado como "variável de ajustamento" e não como "variável objectivo". Por seu turno, o equilíbrio financeiro do sistema foi tomado como "objectivo primordial" e não como "restrição". Na óptica da política social, uma metodologia consistente tem como ponto de partida um conjunto de objectivos sociais a atingir, sendo a prossecução desses objectivos condicionada pela restrição financeira. De acordo com a perspectiva normativa defendida no presente artigo, é fundamental sustentar não só o objectivo de prevenção de pobreza entre os idosos mas também o objectivo de promover uma maior paridade de níveis de vida entre os pensionistas e os seus contemporâneos, por razões de justiça social. Num contexto em que os problemas de financiamento do subsistema se tornam candentes, a realização progressiva de tais objectivos sociais exige que o ajustamento se concretize preferencialmente através das vias que não conflituam com esses objectivos, nomeadamente as que não colocam o ónus do ajustamento sobre os pensionistas. São de referir: outras políticas do lado da despesa acima mencionadas; a elevação das contribuições; ou do aumento da idade da reforma, se o contexto do mercado de trabalho permitir. É de destacar, ainda, a importância de uma regulação macroeconómica mais favorável ao crescimento e ao emprego, pelos seus efeitos positivos no equilíbrio financeiro do sistema.

\section{Observações Finais}

Como foi referido, a teoria económica demonstra que há diversas formas de ajustar os esquemas de pensões para fazer face à longevidade crescente. O governo português decidiu seguir uma via única: reduzir as pensões, colocando o encargo do ajustamento exclusivamente sobre os reformados. Tal opção afigura-se particularmente inapropriada, dado que, em Portugal, os pensionistas auferem um nível médio de prestações reduzido, facto que determina um nível de vida relativamente baixo e um risco de pobreza significativamente superior ao da população total.

É de destacar que a reforma recentemente introduzida em Portugal tem grande alcance, pois representa indubitavelmente um ponto de viragem na filosofia do sistema. Como se viu anteriormente, as pensões de reforma apresentam dois objectivos primordiais, a prevenção da pobreza e a salvaguarda dos níveis de vida no período da reforma. A alteração filosófica de fundo agora introduzida consiste na renúncia à prossecução do segundo objectivo. A intervenção do Estado passa a estar concentrada exclusivamente no primeiro objectivo, sendo a prevenção da pobreza explicitamente considerada uma prioridade política. O nível médio das pensões irá ser reduzido, tendo sido tomado como variável de ajustamento no âmbito de uma política que tem por objectivo principal assegurar o equilíbrio financeiro do sistema.

Ao mesmo tempo, generaliza-se a ideia de que os esquemas contributivos se devem configurar por analogia com os mecanismos seguradores privados. Por um lado, afirma-se a tendência para manter um laço estreito entre contribuições e prestações a nível individual, reflectida na 
definição de uma nova regra de cálculo, que faz depender o valor da pensão das remunerações da totalidade da carreira contributiva. Por outro lado, o valor da pensão, já que o seu cálculo depende do "factor de sustentabilidade", passa a relacionar-se com a esperança média de vida no momento de cessação de actividade. A equidade individual torna-se a norma implícita de justiça.

Na lógica da reforma, a esfera da responsabilidade social pode abranger prestações de natureza não contributiva (do regime não contributivo ou prestações sujeitas a condições de recursos, como o complemento solidário para idosos). Porém, os esquemas de natureza contributiva passam a adquirir um cunho próximo de um mecanismo segurador, sendo relegados para a esfera da responsabilidade individual ${ }^{32}$.

As medidas agora introduzidas no esquema contributivo irão traduzir-se num declínio das taxas de substituição, na sequência da introdução do "factor de sustentabilidade" e da nova fórmula de cálculo das pensões, dependentes, doravante, das remunerações da totalidade da carreira contributiva. Determinar o valor da pensão com base no valor das últimas remunerações ou das remunerações de toda a carreira contributiva tem impacto diferente na taxa de substituição. Como, em geral, as carreiras apresentam níveis remuneratórios superiores nos últimos anos de actividade, quando as prestações dependem das remunerações de toda a carreira, a taxa de substituição é inferior. Em consequência, os rendimentos dos pensionistas, tendo uma relação mais estreita com as remunerações de toda a carreira, distanciar-se-ão do rendimento corrente na sociedade, no momento da reforma.

As novas regras de indexação irão operar no mesmo sentido, moldando trajectórias de rendimento na reforma que se distanciam da evolução geral de rendimentos na sociedade. Caminha-se para uma protecção mínima de rendimento em que a própria revalorização das pensões se desliga da evolução salarial (caso das prestações de nível mínimo) e dos preços (caso das prestações superiores a 1,5 IAS).

As medidas introduzidas conduzem inevitavelmente a uma redução do nível de vida relativo dos pensionistas. Daqui resultará um problema de justiça entre contemporâneos que, na minha perspectiva, é um problema ético relevante. 


Anexo
\begin{tabular}{c|c|cc} 
Quadro 1 - Taxa de crescimento real do "valor mínimo de pensão" (vmp) \\
\hline & Crescimento real do vmp (\%) & & \multicolumn{1}{l}{ Crescimento real do vmp (\%) } \\
\hline 1986 & 12,3 & 1997 & 1,6 \\
\hline 1987 & 52,3 & 1998 & 1,3 \\
\hline 1988 & 3,1 & 1999 & 1,8 \\
\hline 1989 & $-0,3$ & 2000 & 1,5 \\
\hline 1990 & 2,7 & 2001 & 1,5 \\
\hline 1991 & 5,6 & 2002 & 1,9 \\
\hline 1992 & 4,7 & 2003 & 0,7 \\
\hline 1993 & 1,7 & 2004 & 3,1 \\
\hline 1994 & 0,8 & 2005 & 2,0 \\
\hline 1995 & 1,2 & & \\
\hline
\end{tabular}

Fontes: Cálculos efectuados pela autora com base nos "valores mínimos de pensão" estabelecidos em Portaria e nos valores do IPC sem habitação.

\section{Gráfico 1 - Crescimento da pensão média em termos reais}

240

220

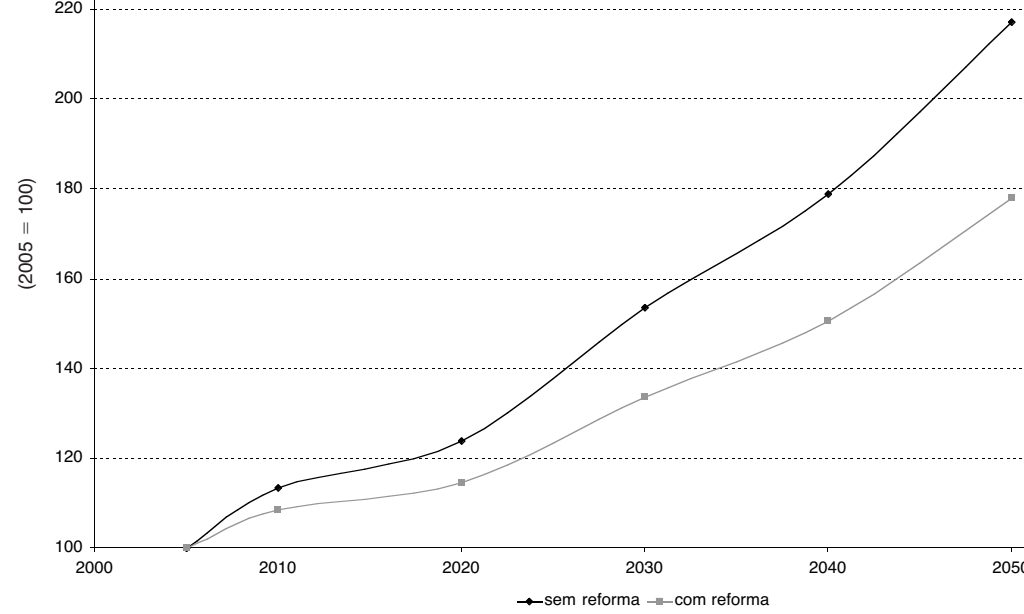

2060 


\section{References}

Atkinson, A. B. (1995) Incomes and the Welfare State - Essays on Britain and Europe, Cambridge, Cambridge University Press.

Atkinson, A. B. (1999) The Economic Consequences of Rolling Back the Welfare State, Cambridge Mass., The MIT Press.

Barr, N. (2001) The Welfare State as Piggy Bank - Information, Risk, Uncertainty, and the Role of the State, Oxford, Oxford University Press.

Barr, N. (2004) Economics of the Welfare State, 4. ${ }^{a}$ Ed., Oxford University Press, Oxford.

Barr, N. (2006) Pensions: Overview of the Issues, Oxford Review of Economic Policy, 22, 1, 1-14.

Barr, N.; Diamond, P. (2006) The Economics of Pensions, Oxford Review of Economic Policy, 22, 1, 15-39.

Barr, B. (1990), Ethics, 100, 503-529; reimpresso in Goodin, R. and Ware, A. (eds.), Needs and Welfare, London, Sage, 73-103.

Blanchet, D.; Villeneuve, B. (1997) Que reste-t-il du débat répartition-capitalisation?, Revue d'Économie Financière, 40, 157-174.

European Commission (2005) National Strategy Report: adequate and sustainable pension systems, Relatório submetido em Julho de 2005 à Comissão Europeia.

[http://ec.europa.eu/employment_social/social_protection/docs/2005/pt_sintese_en.pdf]

European Commission (2006) Adequate and Sustainable Pensions: Synthesis Report, Luxembourg, Office for Official Publications of the European Communities.

Fleurbaey, M. (2002) Retraites, Générations et Catégories Sociales: de l'équité comme contrainte à l'équité comme objectif, Revue d'Économie Financière, 68, 91-111.

Fleurbaey, M.; Michel, P. (1992) Quelle justice pour les retraites?, Revue d'Économie Financière, 23, 47-64.

Gillion, C., Turner, J., Bailey, C.; Latulippe, D. (eds.) (2000) Social Security Pensions, Development and reform, Geneva, International Labour Office.

Math, A. (2001) Quel avenir pour les retraites para répartition en Europe?, Revue de l'IRES, 36, 2, 3-59.

Ministério das Finanças e da Administração Pública (2006) Orçamento de Estado para 2007: Relatório, Outubro, Lisboa.

Ministério do Trabalho e da Solidariedade Social (2006) Linhas Estratégicas da Reforma da Segurança Social, 3 de Maio, Lisboa.

Myles, J. (2002) A New Social Contract for the Elderly? in Esping-Andersen, G. with Gallie, D. et al., Why we need a new Welfare State, Oxford, Oxford University Press, 130-172.

Rein, M.; Turner, J. (1999) Le travail, la famille, l'État et le marché: des sources de revenus composites pour les ménages âgés, Revue Internationale de Sécurité Sociale, 52, 3, 109-125.

Thompson, L. H. (1983) The Social Security Reform Debate, Journal of Economic Literature 21, 4, 1425-1467.

Thompson, L. H. (1998) Older and Wiser: The Economics of Public Pensions, Washington, D.C., The Urban Institute Press. 